\title{
Neoplasia no sítio da colostomia de paciente com megacólon chagásico: relato de caso
}

\author{
Neoplasia at the site of the colostomy of patient with chagasic megacolon: case report \\ THIAGO AGOSTINI BRAGA ${ }^{1}$, ANTONIO BALESTRIM FILHO ${ }^{1}$, BRUNA MEYER RIBEIRO DE MATTOS ${ }^{1}$, \\ GIANCARLO DE SOUZA MARQUES ${ }^{1}$, JOSE JOAQUIM RIBEIRO DA ROCHA ${ }^{1}$, OMAR FÉRES ${ }^{1}$ \\ ${ }^{1}$ Divisão de Coloproctologia do Departamento de Cirurgia e Anatomia da Faculdade de Medicina de Ribeirão Preto da \\ Universidade de São Paulo - Ribeirão Preto (SP), Brasil.
}

BRAGA TA, FILHO AB, MATTOS BMR, MARQUES GS, ROCHA JJR, FÉRES O. Neoplasia no sítio da colostomia de paciente com megacólon chagásico: relato de caso. Rev bras Coloproct, 2011;31(2):197-199.

RESUMO: A neoplasia no sítio da colostomia associada ao megacólon chagásico é uma entidade rara. Os autores relatam caso de um paciente com lesão avançada, o qual foi submetido a tratamento cirúrgico e discutem aspectos relacionados a esta afecção.

Palavras-chave: neoplasia; colostomia; megacólon; doença de Chagas; câncer de cólon.

\section{INTRODUÇÃO}

A confecção de colostomia, com a finalidade de desvio temporário ou definitivo do trânsito intestinal colônico, é um procedimento que não é isento de complicações, que apresentam variação de 15 a $30 \%$, sendo a mais rara o surgimento da neoplasia ${ }^{1}$.

$\mathrm{O}$ adenocarcinoma primário do sítio da colostomia é uma enfermidade rara ${ }^{2,3}$. Há poucas descrições de associação entre megacólon chagásico e neoplasia colorretal.

\section{RELATO DE CASO}

Os autores apresentam um caso de neoplasia em colostomia, em paciente chagásico. J.A.R., 74 anos, sexo masculino, branco, submetido à colectomia segmentar, em outro serviço, aos 55 anos de idade (1998), devido à complicação não especificada da colopatia chagásica, com confecção de transversostomia em alça. Foi submetido a três laparotomias para tentativa de reconstituição do trânsito intestinal, sem sucesso. Evoluiu com hérnia incisional de grande volume.

Trabalho realizado na Divisão de Coloproctologia do Departamento de Cirurgia e Anatomia da Faculdade de Medicina de Ribeirão Preto da Universidade de São Paulo, Ribeirão Preto (SP), Brasil.

Fonte de financiamento: não há

Conflito de interesse: nada a declarar 
Em 2007, paciente procurou o Serviço de Coloproctologia do Hospital das Clínicas de Ribeirão Preto com queixa de dor e sangramento pela colostomia. Ao exame, apresentava lesão vegetante de $15 \mathrm{~cm}$ de diâmetro, no local da colostomia, infiltrando a parede abdominal. Na tomografia de abdômen apresentava lesão vegetante e infiltrativa na parede abdominal, no sítio da colostomia e hérnia incisional de grande volume. Apresentava antígeno carcinoembrionário (CEA) de 0,53.

Foi submetido à ressecção da neoplasia do sítio da colostomia, envolvendo parte da parede abdominal com margens, juntamente à colectomia direita ampliada, ileodescendente anastomose látero-lateral grampeada e ileostomia protetora em alça. O anatomopatológico da peça cirúrgica revelou adenocarcinoma pouco diferenciado de alto grau - classificação T3 N0 M0.

Evoluiu com necrose da parede abdominal aproximada, primariamente em uma extensão de $20 \mathrm{x}$ $12 \mathrm{~cm}$, sendo submetido à realização de retalho microcirúrgico do músculo grande dorsal e enxertia de pele com área doadora da coxa direita, pela equipe de cirurgia plástica.

Posteriormente iniciou quimioterapia adjuvante com 5-fluoracil e leucovorin, com boa evolução até o momento.

\section{DISCUSSÃO}

A presença de carcinoma no sítio da colostomia não é frequente; entretanto, o seu surgimento pode ocorrer ao longo do tempo e cursa com altos índices de morbi-mortalidade ${ }^{1,2,4}$.

A colostomia apresenta os mesmos fatores predisponentes e desencadeantes para o aparecimento do tumor colônico primário, em relação a qualquer um dos seus segmentos ${ }^{1}$.

São descritos, na literatura, fatores de risco para o surgimento de neoplasia no sítio da colostomia, como lesão neoplasia metacrônica, colectomia oncológica com margens ressecadas inadequadas, polipose colônica e, principalmente, a metaplasia colônica secundária à doença inflamatória intestinal, não sendo mencionado casos associados a megacólon chagásico ${ }^{1-5}$.

Pela raridade da associação de megacólon chagásico e câncer, e por ser mais raro ainda o surgimento de neoplasia na colostomia, torna esse caso inusitado (Figuras 1 a 3).

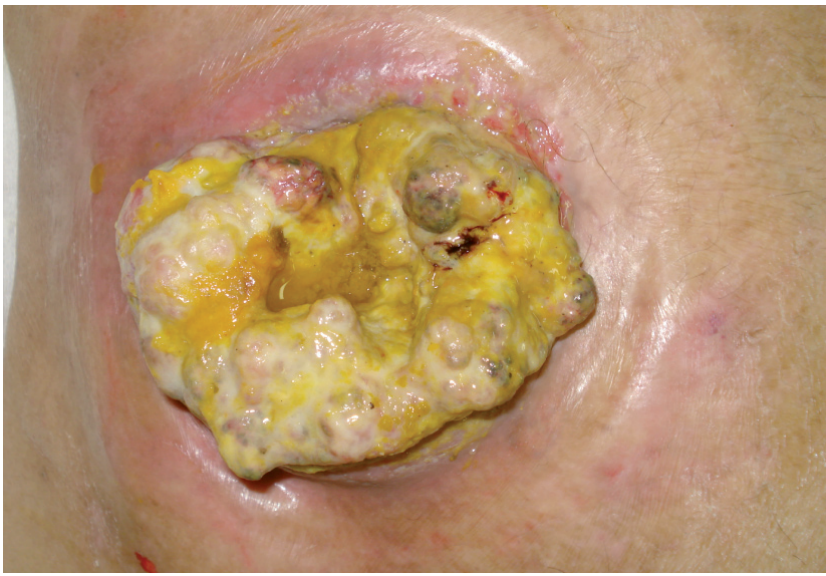

Figura1. Neoplasia na colostomia infiltrando a parede.

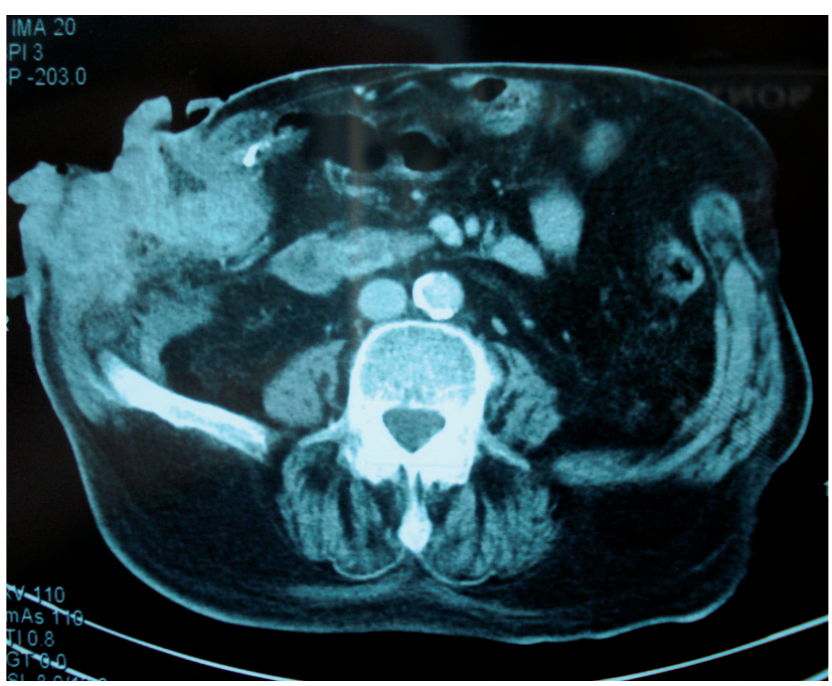

Figura 2. Tomografia mostrando a massa tumoral.

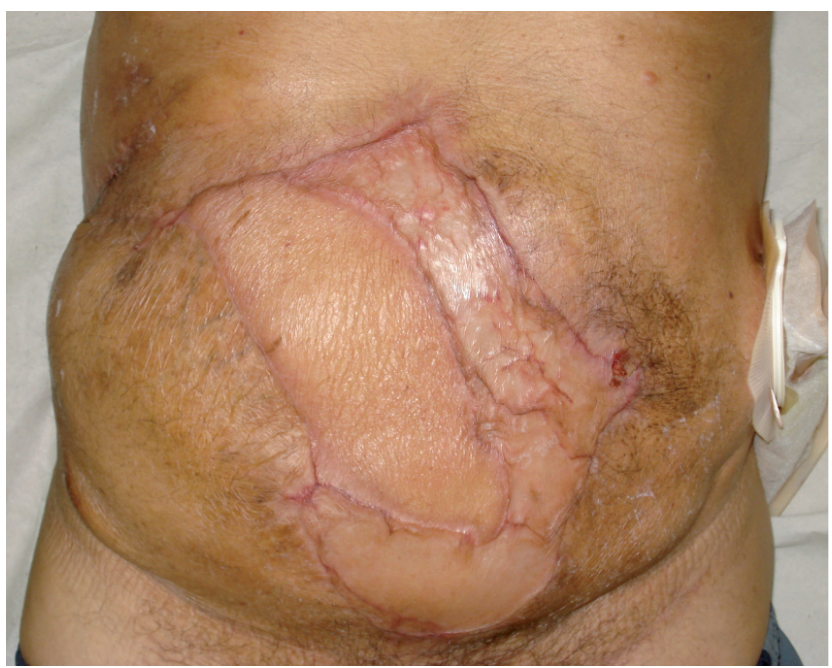

Figura 3. Aspecto final do abdômen após retalho miocutâneo. 
ABSTRACT: Neoplasia at the site of the colostomy associated with chagasic megacolon is a rare clinical event. Here, the authors report the case of a patient with advanced lesion, who had to undergo surgical treatment, and discuss aspects related to this disease.

Keywords: neoplasia; colostomy; megacolon; Chagas disease; colon neoplasm.

\section{REFERÊNCIAS}

1. Salles VJA, Paula PR, Bassi DG, Speranzini MB. Neoplasia no sítio da colostomia: relato de três casos e revisão da literatura. Rev bras Coloproct 2006;26(1):57-60.

2. Adad SJ, Etchebehere RM, Araújo JR, Madureira AB, Lima VGF, Silva AA, et al. Association of chagasic megacolon and cancer of the colon: case report and review of literature. Rev da Soc Bras Med Trop 2002;35(1):63-8.

3. 4. Takami M, Hanada M, Kimura M, Takeuchi N, Takada T. Adenocarcinoma arising at a colostomy site. Report of case. Dis Col Rect 1983;26(1):50-2.

4. .Fagundes JJ, Goes JRN, Coy CSR, Ayrizono MLS, Mochizuki
M, Chadu M, et al. Associação entre megacólon chagásico e câncer do intestino grosso: apresentação de casos e revisão de literatura. Rev Bras Coloproct 2002;22(4):252-6.

5. Salles VJA, Speranzini MB, Bassi DG, Paula PR. Neoplasia occuring at the colostomy site: Report of two cases and review of the literature. Rev Mex Coloproct 2007;13(1):24-6.

\section{Endereço para correspondência:}

Omar Féres

Av. Santa Luzia, 630, Jd. Sumaré - CEP: 14025-090 - Ribeirão Preto (SP), Brasil

E-mail: feresomar@netsite.com.br 